\title{
A rare cause of severe diarrhoea diagnosed by urine metabolic screening: aromatic L-amino acid decarboxylase deficiency
}

\author{
LK Lee *, KM Cheung, WW Cheng, CH Ko, Hencher HC Lee, CK Ching, Chloe M Mak
}

\section{A B S T R A C T}

A 15-year-old Chinese male with infantile-onset hypotonia, developmental delay, ptosis, and oculogyric episodes presented with a history of chronic diarrhoea since the age of 5 years. At presentation, he had an exacerbation of diarrhoeal symptoms resulting in dehydration and malnutrition with a concurrent severe chest infection. In view of his infantile-onset hypotonia, oculogyric crises, and protracted diarrhoea, an autonomic disturbance related to neurotransmitters was suspected. Urine organic acid profiling was compatible with aromatic L-amino acid decarboxylase deficiency. The diagnosis was confirmed based on cerebrospinal fluid analysis and genetic mutation analysis. The patient was treated with a combination of bromocriptine, selegiline, and pyridoxine; a satisfactory reduction in diarrhoea ensued. Our report highlights the importance of urine organic acid screening in infantile-onset hypotonia, especially when accompanied by oculogyric crises, and severe diarrhoea which could manifest as a result of autonomic disturbance.

\section{Hong Kong Med J 2014;20:161-4}

DOI: $10.12809 / \mathrm{hkmj} 133922$

${ }^{1}$ LK Lee *, MB, BS, MRCPCH

${ }^{1} \mathrm{KM}$ Cheung, MB, ChB, FHKAM (Paediatrics)

${ }^{1}$ WW Cheng, MB, ChB, FHKAM (Paediatrics)

${ }^{1} \mathrm{CH}$ Ko, FRCP, RCPS (Glasg)

${ }^{2}$ HHC Lee, FHKCPath, FRCPA

${ }^{2}$ CK Ching, FRCPA, FHKAM (Pathology)

${ }^{2}$ CM Mak, FHKCPath, FHKAM (Pathology)

1 Department of Paediatrics and Adolescent Medicine, Caritas Medical Centre, Shamshuipo, Hong Kong

${ }^{2}$ Chemical Pathology Laboratory, Department of Pathology, Princess Margaret Hospital, Laichikok, Hong Kong

* Corresponding author: samantha_1703@hotmail.com

\section{Case report}

A 15-year-old Chinese male, with neurological impairment and a history of chronic diarrhoea, presented with intractable diarrhoea after an episode of severe pneumonia with a pleural effusion that eventually resolved after 8 weeks of antibiotic therapy. The chronic watery diarrhoea (averaging 7 motions/day) persisted despite cessation of antibiotics for 1 month. His body weight had dropped from $26.6 \mathrm{~kg}$ to $21.7 \mathrm{~kg}$. Hydration and electrolyte balance was maintained by $1.7 \mathrm{~L} /$ day of lactose-andsucrose-free elemental formula and intravenous fluid, supplemented by potassium $(1.8 \mathrm{mmol} / \mathrm{kg} /$ day). Serial infection screens for rotavirus, norovirus, bacterial culture, ova, cysts, and Clostridium difficile toxin were negative. Blood tests yielded a reduced plasma albumin level $(24 \mathrm{~g} / \mathrm{L}$; reference range, 37 $47 \mathrm{~g} / \mathrm{L})$, but the blood lymphocyte count $\left(2 \times 10^{9} / \mathrm{L}\right)$ and immunoglobulin levels (IgG $1980 \mathrm{mg} / \mathrm{dL}$, IgA $447 \mathrm{mg} / \mathrm{dL}$, IgM $111 \mathrm{mg} / \mathrm{dL})$ were normal. Intravenous octreotide (mimics somatostatin) up to $200 \mu \mathrm{g}$ per day was given for 1 week with a view to easing his diarrhoea, ${ }^{1}$ but no obvious benefit ensued.

On reviewing the history, the patient had global developmental delay and truncal hypotonia since the age of 8 months. He became bed-bound aged 1.5 years and also had a history of recurrent aspiration pneumonia since early childhood. His recurrent pneumonia became worse in 2008 (aged 11-12 years). After a gastrostomy and fundoplication when he was 13 years old, his condition improved partially, but he still endured two to three episodes of pneumonia every year. At the age of 15 years he had an episode of pneumonia associated with a pleural effusion, which was by far the most severe since his gastrostomy and fundoplication. Bilateral ptosis had been noted when he was 3.5 years old, and brief episodes of up-rolling eyeballs were reported since the age of 4 years. The electroencephalogram showed sharp waves over both hemispheres, especially over both temporal and the left centro-temporal areas. The patient was treated with carbamazepine, but there was minimal improvement of his abnormal eye movements. Metabolic workup, including thyroid function tests, and determination of ammonia, lactate, and glucose levels and urine amino acids screening yielded nil abnormal. Magnetic resonance imaging of the brain, muscle biopsy, sural nerve biopsy, the Tensilon test, hearing and ophthalmological screening were all unremarkable. Genetic studies excluded spinal muscular atrophy, myotonic dystrophy, and Fragile $\mathrm{X}$ syndrome. At the age of 5 years, he started having chronic watery diarrhoea, which occurred after each episode of aspiration pneumonia with respiratory 


\section{利用尿液代謝檢查找出嚴重腹瀉的罕見病因： 芳香 $L$-氨基酸脫羧酶缺乏症}

李勵嘉、張嘉明、鄭蕙惠、高震雄、李漢芝、程楚君、麥苗

一名15歲的華籍男性, 自嬰兒期開始已出現肌張力低下、發育遲緩、 上瞼下垂和動眼危象。此外, 他從五歲開始已有慢性腹瀉。病人病發 時因一次嚴重肺部感染而出現腹瀉, 並導致脱水和營養不良。由於他 自小已有肌張力低下、動眼危象和長期腹瀉, 懷疑病因可能是與神經 遞質有關的自律神經系統功能失調。替病人進行尿液代謝檢查發現與 芳香 L-氨基酸脱羧酶缺乏症吻合, 最後根據腦脊液和基因突變分析為 病人確診。病人接受bromocriptine、selegiline和pyridoxine的合併治 療, 腹瀉次數得以緩減。本報告顯示為嬰幼兒期已出現肌張力低下的 病人進行尿有機酸篩查的重要性, 尤其是當病人併發動眼危象時, 而 嚴重腹瀉可能由於自律神經系統失調造成。 failure. Stool microscopy showed one white cell per high power field, yielded no fat globules, ova, or cysts. Clostridium difficile cytotoxin and stool cultures were negative. Stool-reducing substance was undetectable. Serum cortisol was normal. Four months after a trial of semi-elemental and elemental formula and the use of anti-diarrhoeal medication, there was some improvement of his diarrhoea. The patient's body weight remained at the third percentile with a fluid intake of approximately $1.3 \mathrm{~L} /$ day, and at that time his diarrhoea was regarded as functional.

The patient was transferred to our unit at the age of 6 years. Aged 9 years, he had an unexplained witnessed cardiac arrest in the Developmental Disabilities Unit of the Caritas Medical Centre, which was confirmed to be asystolic. Consequently, the patient suffered permanent neurological damage. When he was 11 years old, there was an episode of protracted hypotension with bradycardia (for 5 hours), which followed sedation (with diazepam $0.1 \mathrm{mg} / \mathrm{kg}$ ) for an oesophagogastroduodenoscopy. Aged 13 years, he had an exacerbation of severe watery diarrhoea after undergoing laparoscopic fundoplication and gastrostomy, which was followed by marked weight loss $(3.9 \mathrm{~kg})$ over 1 month. There was no steatorrhoea; the patient's lipid profile was normal and stool cultures were again negative. The diarrhoea ameliorated after he started feeding with semi-elemental prebiotic formulas, as well as treatment with diphenoxylate and atropine. $\mathrm{He}$ regained his body weight reaching $26.6 \mathrm{~kg}$ over the subsequent year. The entire episode was attributed to postoperative dumping syndrome.

In view of the multisystem involvement, urine metabolic profiling was performed. This showed hyper-excretion of vanillactate, 3-O-methyl-DOPA and $\mathrm{N}$-acetyl-vanilalanine with hypo-excretions of 5-hydroxyindoleacetic acid (5-HIAA) and vanillylmandelic acid. The result was compatible with aromatic L-amino acid decarboxylase (AADC) deficiency. The diagnosis was confirmed by cerebrospinal fluid examination, which showed a marked increase in 3-O-methyl-DOPA (365 $\mathrm{nmol} / \mathrm{L})$ and 5-hydroxytryptophan (72 $\mathrm{nmol} / \mathrm{L})$, with undetectable 5-HIAA $(<5 \mathrm{nmol} / \mathrm{L})$ and homovanillic acid $(<5 \mathrm{nmol} / \mathrm{L})$. Mutation analysis of the DOPA decarboxylase $(D D C)$ gene revealed a heterozygous c.714+4A $>\mathrm{T}$ and c.1312T $>\mathrm{C}$ (p.Cys438Arg) mutation. This particular mutation NM_000790.3(DDC):c.714+4A $>$ T was known to cause AADC deficiency and was by far the most common mutation causing this condition in the Chinese. ${ }^{2}$ The patient was given a combination of bromocriptine $2.5 \mathrm{mg}$ twice a day, selegiline $5 \mathrm{mg}$ daily, and vitamin B6 $200 \mathrm{mg}$ twice daily for the next 6 months and appeared to have a good response, as inferred by the reduced frequency of diarrhoeal episodes (2-3 times/day), weight gain to $27.7 \mathrm{~kg}$ (at latest follow-up), and diminished recourse to potassium supplementation $(0.7 \mathrm{mmol} / \mathrm{kg} / \mathrm{day})$. He also became more tolerant of higher milk-drip rates (from 50 to $300 \mathrm{~mL} / \mathrm{h}$ ) and volume of fluid intake (1.5 L/day). He has had no recurrences of severe diarrhoea accompanying subsequent illness episodes.

\section{Discussion}

Deficiency of AADC is a rare metabolic disorder; worldwide, less than 100 patients have been reported. ${ }^{3}$ The patient commonly presented at the age of less than 1 year, with developmental delay, dystonia, and autonomic dysfunction. Diarrhoea was reported in $50 \%$ of the patients in one Taiwan series, ${ }^{4}$ however, severe diarrhoea was seldom reported. This case report highlights the importance of a high index of suspicion for neurotransmitter disease in infantileonset hypotonia with extrapyramidal features, and shows that severe diarrhoea can be the predominant feature of an autonomic disturbance.

Since AADC is an important enzyme in monoamine biosynthesis (Fig), if lacking it results in dopamine and norepinephrine deficiency. Norepinephrine deficiency results in unopposed acetylcholine activity, leading to increased intestinal motility and relaxation of sphincters. The resultant reduction in intestinal transit time may impair absorption. Moreover, unopposed acetylcholine activity stimulates intestinal secretion, which also contributes to diarrhoea. ${ }^{5}$ A shorter transit time in the distal small bowel has also been reported in diabetic patients with autonomic dysfunction. ${ }^{6,7}$ The rapid passage of chyme into the large bowel results in impaired water and electrolyte absorption and hence diarrhoea, for which a defect in alpha-adrenergic activity is thought to play a key pathological role. ${ }^{6,7}$ The autonomic features present in our patient (bilateral ptosis, and protracted periods of 
Tyrosine

Tyrosine hydroxylase $\square$
3-O-methyldopa
L-dopa*

Tryptophan

$\square$ Tryptophan hydroxylase

\section{5-Hydroxytrytophan}

\section{AADC \\ BH4 and pyridoxine* dependent}

\section{Dopamine*}

\section{DBH $\mathcal{L}$ Y COMT/MAO*}

Norepinephrine<smiles>c1ccccc1</smiles>

\section{Epinephrine}

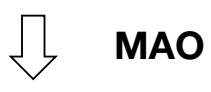

$\underline{\text { Homovanillic acid }}$
Serotonin

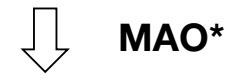

\section{5-Hydroxyindoacetic acid}

\section{Vanillylmandelic acid}

FIG. Pathway of monoamines synthesis

3-O-methyldopa is further metabolised to $\mathrm{N}$-acetyl-vanilalanine and vanilpyruvic acid (the precursor of vanillactate). Common analytes in cerebrospinal fluid/urine are underlined

Abbreviations: AADC = aromatic L-amino acid decarboxylase; COMT = catechol-O-methyl-transferase; $\mathrm{DBH}=$ dopamine beta-hydroxylase; $\mathrm{MAO}=$ monoamine oxidase

* Target sites for therapy in AADC deficiency

hypotension with bradycardia) are also compatible with AADC deficiency. Moreover, the unexplained cardiac arrest could have been due to unopposed vagal tone; evidently, in AADC deficiency a stress as minor as catheter insertion can result in severe bradycardia and cardiac arrest. ${ }^{8}$ Autonomic dysfunction was prominent in our patient, and potentially could account for the severe diarrhoea.

In the literature, patients have been diagnosed during infancy or early childhood owing to movement disorders or autonomic features, including truncal hypotonia, hyper-reflexia, oculogyric crises, ptosis, sweating, nasal congestion, and labile blood pressures and heart rates. Owing to a reduced lifespan, clinical features in late childhood are rarely reported. The presentation with chronic diarrhoea punctuated by episodic exacerbations of dehydration and malabsorption with superadded neurological impairment may result in the characteristic clinical features of AADC deficiency in the late childhood. Although the diarrhoea in our patient responded favourably to the combination of dopamine receptor agonist, monoamine, oxidase inhibitor and pyridoxine (the cofactor for AADC), no improvement in cognitive or motor function was observed. According to the literature, the clinical efficacy of dopamine agonists, monoamine oxidase inhibitors, AADC cofactors (pyridoxine and pyridoxal phosphate $[\mathrm{PLP}])$, and anticholinergics remains variable. ${ }^{2}$ Commonly used dopamine agonists aimed at improving motor deficits include bromocriptine and pergolide. Selegiline has been reported to improve oculogyric crises, muscle tone and strength, gastro-intestinal function, hypersalivation and sleep patterns, but according to some reports such effects were transient. ${ }^{9}$ Pyridoxine (usual dosage of 100-400 $\mathrm{mg} /$ day) was commonly added to the treatment with the aim of boosting AADC activity through cofactor excess, but has not been reported to significantly improve clinical outcomes. The use of pyridoxine $145 \mathrm{mg} / \mathrm{kg} /$ day had been reported, but has resulted in significant gastro-intestinal side-effects that warranted dose reduction. ${ }^{9}$ There was evidence that PLP, the active metabolite of pyridoxine, was 
important for AADC stability. It was postulated that the direct enteral administration of this compound could be dephosphorylated by intestinal phosphatases, absorbed into the bloodstream, and cross the blood-brain barrier. Conceivably, this could provide a more efficient supply of PLP to the brain than pyridoxine (that requires multiple metabolic steps). ${ }^{9,10}$ However, the necessary efficacious dose has not been established ${ }^{9}$ and clinical outcomes still remain unclear. At the moment, even with early diagnosis, the overall prognosis of patients with AADC deficiency remains guarded, particularly in terms of neurological outcomes and autonomic disturbance. $^{2}$

\section{References}

1. Farthing MJ. Octreotide in the treatment of refractory diarrhoea and intestinal fistula. Gut 1994;35(3 Suppl):S5-10.

2. Brun L, Ngu LH, Keng WT, et al. Clinical and biochemica features of aromatic L-amino acid decarboxylase deficiency. Neurology 2010;75:64-71.

3. Lee HC, Lai CK, Yau KC, et al. Non-invasive urinary screening for aromatic L-amino acid decarboxylase deficiency in high-prevalence areas: a pilot study. Clinica Chimica Acta 2012;413:126-30.

4. Lee NC, Shieh YD, Chien YH, et al. Aromatic L-amino acid decarboxylase deficiency in Taiwan. Eur J Paediatr Neurol 2009;13:135-40.

5. Ganong WF. Review of medical physiology. 20th ed. New York: Lange; 2001.

6. Rosa-e-Silva L, Troncon LE, Oliveira RB, Foss MC, Braga FJ, Gallo Júnior L. Rapid distal small bowel transit associated with sympathetic denervation in type I diabetes mellitus. Gut 1996;39:748-56.

7. Chang EB, Bergenstal RM, Field $M$. Diarrhea in streptozocin-treated rats. Loss of adrenergic regulation of intestinal fluid and electrolyte transport. J Clin Invest 1985;75:1666-70.

8. Swoboda KJ, Saul JP, McKenna CE, Speller NB, Hyland K. Aromatic L-amino acid decarboxylase deficiency: overview of clinical features and outcomes. Ann Neurol 2003;54 Suppl 6:S49-55.

9. Allen GF, Land JM, Heales SJ. A new perspective on the treatment of aromatic L-amino acid decarboxylase deficiency. Mol Genet Metab 2009;97:6-14.

10. Clayton PT. B6-responsive disorders: a model of vitamin dependency. J Inherit Metab Dis 2006;29:317-26. 